\title{
EXPECTATIVAS E NECESSIDADES DE ACOMPANHANTES DE CRIANÇAS NA CONSULTA DE SAÚDE
}

\author{
NEEDS AND EXPECTATIONS OF ADULTS WHO BRING \\ CHILDREN AT HEALTH CONSULTATION
}

\author{
Luana Conceição Fortes Assis ${ }^{1}$
}

Maria de La Ó Ramallo Veríssimo ${ }^{2}$

Assis, LCF e Veríssino, MR. Expectativas e necessidades de acompanhantes de crianças na consulta de saúde. Rev. Bras. Cresc. e Desenv. Hum. 2010; 20(2): 317-329.

\section{Resumo:}

A atenção à criança implica responder às expectativas e necessidades de seus cuidadores, particularmente na atenção básica, pois são eles os responsáveis por efetivar as ações terapêuticas, de promoção e manutenção da saúde infantil no domicílio. Objetivo: identificar expectativas e necessidades de acompanhantes de crianças acerca das consultas de saúde. Método: estudo qualitativo, descritivo e exploratório, com análise do conteúdo de entrevistas a trinta acompanhantes, em duas Unidades Básicas de Saúde de São Paulo. Resultados: os acompanhantes, vinte e uma mães e nove outros familiares, manifestam expectativas de uma consulta de saúde resolutiva, garantida por relações interpessoais de atenção e respeito, que correspondem a três grupos de necessidades: 1) garantia de acesso a todas as tecnologias, com avaliações clínicas detalhadas e exames que forneçam evidências confiáveis sobre a saúde da criança; 2) vínculo com um profissional, mediante atenção, segurança, carinho, interesse e diálogo; 3) autonomia e auto-cuidado na escolha do modo de "andar a vida", mediante respeito às dúvidas e preocupações do acompanhante. Assim, para os acompanhantes, a assistência efetiva é aquela baseada na compreensão empática da pessoa e no atendimento às diversas necessidades sentidas. Profissionais devem não só esclarecer as dúvidas e preocupações dos acompanhantes, como também proporcionar relações consistentes, gerando confiança no atendimento e nas recomendações.

Palavras-chave: saúde da criança; determinação de necessidades de cuidados de saúde; atenção primária de saúde.

Enfermeira.

2 Prof ${ }^{a}$ Dr $^{\mathrm{a}}$ do Departamento de Enfermagem Materno-infantil e Psiquiátrica da EEUSP. mdlorver@usp.br Trabalho desenvolvido com apoio do Programa Institucional de Bolsas de Iniciação Cientifica do Conselho Nacional de Desenvolvimento Cientifico e Tecnológico (CNPq).

Correpondência para: luana_cfa84@hotmail 


\begin{abstract}
The care of children must respond to the expectations and needs of their caregivers, particularly in primary care because they are responsible for effecting the therapeutic action, promotion and maintenance of child health at home. Objective: To identify expectations and needs of children caregivens of about health consultations. Method: a qualitative, descriptive and exploratory, with content analysis of interviews with thirty companions, two Basic Health Units in São Paulo. Results: the accompanying twenty-one mothers and nine other family members, express expectations of a query resolving health, guaranteed by the interpersonal relationships of care and respect, which represent three groups of needs: 1) ensuring access to all technologies, with detailed clinical evaluations and tests that provide reliable evidence on child health, 2) bond with a professional, through attention, security, affection, interest and dialogue, 3) autonomy and self-care in choosing the way of "living life", in regard to questions and concerns of the companion. For the companions, the effective care that is based on empathic understanding of people and in meeting the diverse needs. Professionals must not only clarify the doubts and concerns of the companions, but also provide consistent relationships, generating confidence in the service and recommendations.
\end{abstract}

Key words: child health (public health); needs assessment; primary health care.

\section{INTRODUÇÃO}

Na atenção à saúde da criança, é estreita a relação entre Educação em Saúde e Promoção da Saúde, visto que as ações implementadas em todos os níveis de atenção, além de tratar e ou prevenir doenças, destinam-se, também, a promover o crescimento e desenvolvimento infantil, numa perspectiva de qualidade de vida.

No referencial da Promoção, torna-se imperativa a análise das necessidades de saúde desde a perspectiva do usuário, pois essas não estão a uma dimensão sempre considerada. Incorporálas no processo de elaboração das políticas de saúde implica em procurar estratégias apropriadas para sabê-las e para estudar seu impacto nos custos da atenção à saúde e na redução das desigualdades na saúde entre comunidades ${ }^{1,2}$.

O relacionamento entre médicos e pais não é sempre caracterizado por serenidade, entendimento mútuo e satisfação ${ }^{3,4}$. Em particular, a ansiedade e as expectativas dos pais, bem como a ansiedade do médico e seu desejo de satisfazer às expectativas presumidas, com mútua dificuldade de comunicação, são fatores que podem ter conseqüências por todo o curso da consulta, des- de a formulação do diagnóstico e prescrição farmacológica até a compreensão dos objetivos da terapia pelo paciente e sua satisfação com o tratamento.

Muitas consultas realizadas pelos profissionais são pontuais, usualmente relacionadas com a atenção aos sintomas que a criança apresenta e a administração de medicamentos. Cabem, portanto, algumas perguntas: Quais são as necessidades dos cuidadores ao procurarem pelo atendimento de saúde para a criança? Que tipo de conduta adotada por médicos e enfermeiros é essencial às necessidades dos acompanhantes das crianças? A mãe busca no serviço que suas dúvidas e anseios sejam resolvidos, e seu envolvimento com o serviço e a valorização de seus conhecimentos e valores levam-na a se interessar e participar das decisões tomadas em relação à criança ${ }^{5}$. Entretanto, a negligência na atenção às necessidades emocionais maternas se destaca como um problema ${ }^{6}$. O fato de a mãe não ser considerada como sujeito do cuidado no momento do atendimento à criança, coloca a ela um papel apenas instrumental para o 
profissional de saúde, contrário a uma abordagem emancipatória.

Embora haja concordância quanto à importância dos conceitos de necessidade humana e de necessidade de saúde para a orientação do trabalho em saúde, ainda não é possível identificar consensos amplamente aceitos.

Estudo relativamente recente que analisou a produção nacional sobre o tema verificou a utilização ampla do termo necessidade no senso comum, como também que os serviços de saúde têm adotado perspectivas operacionais do conceito, sendo as necessidades de saúde recortadas pela doença e "respondidas com o consumo de um procedimento de saúde majoritariamente, a consulta médica"' .

Esta lógica da oferta de atos de saúde para serem consumidos veio orientando o sistema sanitário brasileiro por décadas e o modelo de atenção biomédico propiciou a hegemonia do saber médico, em detrimento de outros e mesmo do saber da população.

A mudança dessa lógica demanda a definição de uma nova centralidade: a das necessidades em saúde. Apreender as necessidades em saúde passa por criar um espaço de poder para os usuários na negociação do cuidado em saúde, dentre outros aspectos. Tal lógica está presente na atual proposta de reformulação do modelo assistencial, a Política Nacional de Humanização da Atenção e Gestão (HumanizaSUS) $^{8,9}$.

Proposta pelo Ministério de Saúde desde 2003, a Humaniza SUS visa provocar inovações nas práticas gerenciais e de produção de saúde, propondo para os diferentes implicados nestas práticas o desafio de superar limites e experimentar novas formas de organização dos serviços e novos modos de produção e circulação de poder. Aposta na indissociabilidade entre os modos de produzir saúde e os modos de gerir os processos de trabalho, entre atenção e gestão, entre clínica e política, entre produção de saúde e produção de subjetividade, reorientando as práticas para contemplar os sujeitos em sua integralidade e fortalecer o trabalho em equipe $e^{8,9}$.

Neste sentido, a taxonomia de Matsumoto $^{10}$ traz importante contribuição para pensar as necessidades em saúde do usuário como elemento central das práticas, pois possibilita organizar a leitura das necessidades na perspectiva da integralidade.

Dada a importância de focar a atenção no sujeito e buscando analisar se esse quadro vem sendo superado, face às abordagens mais atuais da atenção básica, objetivou-se identificar expectativas de acompanhantes sobre as consultas médicas e de enfermagem à criança, bem como as necessidades subjacentes a elas.

\section{MÉTODO}

Estudo realizado em duas Unidades Básicas de Saúde (UBS), na região do Butantã (São Paulo), selecionadas por conveniência, não diferenciadas das demais unidades da região quanto às demandas pediátricas e características dos trabalhadores.

Obteve-se aprovação de Comitê de Ética em Pesquisa da Secretaria Municipal de Saúde (CAAE $n^{\circ}$ 0037.0.162.196-07) e garantiu-se participação livre e esclarecida bem como o anonimato dos sujeitos. Os participantes do estudo foram acompanhantes das crianças às consultas de saúde nas UBS sendo que por 'consulta de saúde' este estudo refere-se às consultas médicas e de enfermagem.

A coleta foi realizada num período de três meses, encerrando-se quando da saturação das informações. Os acompanhantes que aguardavam a consulta médica ou de enfermagem da criança eram esclarecidos sobre o estudo e indagados sobre o interesse em participar. Aos interessados, apresentu-se o Termo de Consentimento Livre e Esclarecido e, após concordarem e assinarem o termo, iniciava-se a entrevista.

As entrevistas foram conduzidas a partir de questões abertas sobre expectativas e 
demandas frente à consulta: Por que a senhora veio para esta consulta? Qual é o motivo da consulta? A senhora costuma freqüentar esse posto? Para que/ em que situações? A senhora sabe quem vai atender seu filho(a)? Como a senhora acha que será a consulta? Como a senhora gostaria que fosse a consulta? Quando a consulta não é como a senhora queria, como a senhora se sente? E o que a senhora faz? O que é uma boa consulta para a senhora? O que é uma consulta ruim para a senhora?

Os relatos transcritos integralmente da gravação de voz foram submetidos à análise temática de conteúdo e organizados em temas que emergiram das falas. Os temas foram então cotejados com a taxonomia de Matsumoto ${ }^{10}$, que descreve quatro grandes categorias de necessidades: 1) Necessidade de boas condições de vida 2) Necessidade de ga- rantia de acesso a todas as tecnologias; 3) Necessidade de ter vínculo com um profissional ou equipe; 4) Necessidade de autonomia e autocuidado na escolha do modo de "andar a vida".

\section{RESULTADOS}

Foram entrevistados 30 acompanhantes, sendo a maioria de mães (21). Os demais eram familiares que também se incumbiam do cuidado da criança: avós (4), tias (2), pais (2) e bisavó (1). Suas idades variaram de 15 a 70 anos, sendo a média de 34,2 anos e a mediana de 41 anos; a escolaridade de 70\% era inferior ao ensino médio. Em relação às ocupações, $63 \%$ não exerciam ocupação remunerada no momento, por ser do lar, estudante, estar desempregada (Tabela 1).

Tabela 1: Caracterização dos acompanhantes das crianças. São Paulo - 2007.

\begin{tabular}{lcc}
\hline Escolaridade & N & \% \\
\hline Ensino Fundamental incompleto & 11 & 36,7 \\
Ensino Fundamental completo & 4 & 13,3 \\
Ensino Médio incompleto & 6 & 20,0 \\
Ensino Médio completo & 8 & 26,7 \\
Analfabeta & 1 & 3,3 \\
\hline Total & 30 & 100,0 \\
\hline Ocupação & $\mathbf{N}$ & $\mathbf{\%}$ \\
Do lar & 8 & 26,7 \\
Sem ocupação/desempregada & 8 & 26,7 \\
Diarista/empregada doméstica & 3 & 10,0 \\
Aposentada & 3 & 10,0 \\
Recepcionista/atendente & 2 & 6,6 \\
Outras* & 6 & 20,0 \\
\hline Total & 30 & 100,0 \\
\hline
\end{tabular}

*Ajudante geral, motorista, estudante, arrumadeira, promotor de evento. 
Quanto às idades das crianças, a metade era menor de um ano, com maioria abaixo de três anos (Tabela 2).

Tabela 2: Distribuição das idades das crianças. São Paulo, 2007

\begin{tabular}{|c|c|c|}
\hline \multicolumn{2}{|c|}{ Idade } & \multirow{2}{*}{$\frac{\mathbf{N}}{15}$} \\
\hline 0 & — 1 & \\
\hline 1 & 13 & 7 \\
\hline 3 & —6 & 1 \\
\hline 6 & 19 & 4 \\
\hline 9 & $\vdash 12$ & 2 \\
\hline & $\longmapsto 15$ & - \\
\hline & $\longmapsto$ & 1 \\
\hline \multicolumn{2}{|c|}{ Total } & 30 \\
\hline
\end{tabular}

O principal cuidador de 23 crianças era a mãe e outro familiar e, das demais sete, outros familiares ou amigos. A maioria das crianças não frequentava unidade de educação, duas frequentavam creche e sete frequentavam escola ou pré-escola.

Apenas três acompanhantes referiram não saber quem iria fazer a consulta da criança e uma pessoa identificou a categoria do profissional equivocadamente.

Quanto aos motivos da busca de consulta na UBS, geralmente foram os agravos de saúde, mas também o acompanhamento do crescimento e desenvolvimento da criança, a vacinação de rotina e a verificação de resultados de exames.

A maioria dos participantes referiu que frequenta a UBS especialmente para tratar a saúde de suas crianças, mas também a das mães e avós, sendo os homens percebidos como mais resistentes à utilização do serviço de saúde. Assim, destacam-se como razões de utilização da unidade consultas pediátricas, puericultura, medicações e vacinação, seguidas de consultas ginecológicas, tratamento de pressão e diabetes, em caso de adultos. Entretanto, nem sempre a UBS é a primeira opção para busca de atenção, seja pela percepção de que há es- cassez profissional para atendimento, seja por acesso a convênio de saúde, considerado de maior confiança.

A seguir, apresentam-se os temas identificados nas entrevistas.

\section{Expectativas dos acompanhantes quanto às consultas de saúde}

Em geral, as expectativas dos acompanhantes em relação à consulta centram-se em obter resposta a dúvidas acerca da situação de saúde da criança, mas também se referem às previsões sobre como será o atendimento.

E12: "Acho que como foram todas as outras, a mesma coisa, peso, medir ele".

E20: "Que ela fale pra mim o que devo fazer, eu já tenho outros dois filhos, como os dois nunca tiveram isso no umbigo, é o primeiro, então estou meia com medo (...) Tenho muitas dúvidas sobre ele (...) quero que ela avalie".

Em alguns casos, evidencia-se a expectativa de um bom relacionamento interpessoal, na forma de atenção, segurança, carinho e interesse por parte do profissional ao conseguir transmitir isso ao paciente, criança e ao acompanhante.

E4: "Eu já passei com ela antes. Acho que vai ser atenciosa, como sempre, ela cuida bem, ela dá atenção, acho que é assim”.

Para grande parcela dos acompanhantes, o atendimento corresponde às suas expectativas, pois segue certo padrão previsível de ações como pesar, medir, examinar o corpo da criança. Ainda quando não conhecem o profissional que irá atender a criança, acreditam que não haverá mudanças no modo de atendimento.

E23: "Pelo que as outras pessoas já passaram (...) ela atende muito bem, que é bem minuciosa, que examina bem”.

E13: "Não sei, cada vez que eu venho aqui é um profissional diferente (...) venho tantas vezes que acho que será tudo igual, o mesmo diagnóstico". 
Apenas um sujeito relatou a expectativa de diminuição do tempo de permanência no serviço de saúde para ser atendido.

E13: "Sei que não é um pronto socorro, então não tem como querer um atendimento imediato, mas eu gostaria que fosse mais rápido, mais ágil”.

Assim, geralmente, há expectativas de encontrar respostas confiáveis, o que é possível quando a consulta é boa, ou satisfatória, como se apresenta a seguir.

\section{Consultas boas}

Os acompanhantes consideram boa ou satisfatória a consulta que ocorre em clima de atenção, carinho, interesse, igualdade no atendimento e diálogo, destacando assim as relações interpessoais como ponto central.

E16: "Consulta boa seria aquela em que o médico dá toda atenção possível pra criança (...) e se importa com a situação, com o que a gente fala (...)”.

Da mesma forma, os sujeitos fazem referências à busca de evidências por meio de exames laboratoriais, exame físico, histórico do paciente, levando à identificação do diagnóstico e fatores relacionados ao problema, propondo uma solução e transmitindo ao acompanhante confiança e tranqüilidade.

E13: "Acho que fazer o exame físico completo (...) dar o diagnóstico certo”.

A boa consulta é aquela em que o profissional dá respostas às dúvidas da família sobre a situação de saúde da criança, incluindo o diagnóstico, a orientação do tratamento e as precauções para evitar que a doença reincida.

E5: "explicam o que está acontecendo, o que não está, como que deve ser”.

Com relação às explicações oferecidas pelos profissionais, quase a totalidade dos sujeitos da pesquisa relata receber orientações adequadas. Apenas uma pessoa relatou que há profissionais que utilizam termos técnicos durante a explicação.

E25: "Tem alguns que explicam, mas às vezes têm outros que explicam na língua dos médicos e a gente não entende nada. Mesmo assim eu volto a perguntar e eles respondem claramente (...)".

As explicações sobre procedimentos transmitidas, geralmente, de forma verbal, e sobre as medicações registradas na receita, são percebidas como suficientes para o cuidado da criança em casa.

E1: “(...) verbalmente, às vezes ele escreve, uma receita que eu não entendo, ele fala: 'é isso aqui, aqui, aqui' ele explica tudo, senão eu não dou não”.

Assim, a boa consulta é resolutiva porque fornece respostas às dúvidas e garante uma situação de confiança. A confiança na avaliação e no interesse do profissional em cuidar da criança é determinante da confiança em seu diagnóstico e tratamento.

Por outro lado, não são oferecidas explicações mais detalhadas aos usuários, restringindo-se ao diagnóstico, sem esclarecer suas causas ou conseqüências, além de não haver preocupação em confirmar sua alfabetização. Ao não receberem muitas explicações, os usuários podem sentir que o diagnóstico não foi feito com precisão e coerência, sentindo insegurança sobre a situação de saúde da criança.

E25: "é muito raro explicar (...) eles falam, ela está com uma infecção, mas não explicam aonde, da onde veio, como que eu faço pra não pegar".

E17: "Não pergunta, aí minha filha lê (...) Acho que o médico está ali para passar a receita (...) ele fala o que é pra fazer, aí a gente faz”.

Em função de experiências anteriores, há acompanhantes que manifestam receio de serem submetidos a consultas ruins, como se descreve a seguir.

\section{Consultas insatisfatórias}

Em oposição à boa consulta, a consulta é caracterizada como ruim ou insatisfatória quando o profissional demonstra descaso, ou não é atencioso, não respeita, não escuta as 
demandas do acompanhante. A maioria dos sujeitos aponta ser inviável fazer bons diagnósticos nessas situações e que a precária identificação do problema reflete no tratamento da criança, pois o responsável não tem parâmetros para dar seguimento ao cuidado.

E18: “A criança está com febre, ele dá remédio pra febre e manda ir embora (...) Aí chega a noite, a criança não dorme, aí você vai de novo (...)”.

A consulta ainda é considerada ruim quando o diagnóstico é equivocado, por ausência de evidências, sem informações de exames laboratoriais, exame físico, medidas antropométricas, histórico; o profissional não esclarece o problema identificado e não fornece explicações, referentes ao diagnóstico da criança, ao tratamento a ser seguido, às precauções para evitar que a doença reincida e às dúvidas do responsável.

E12: "O médico ser ignorante, não explicar as coisas. Eu já saí com dúvidas daqui”.

\section{Ações do profissional e o clima de confiança}

Ao definirem o que consideram uma boa consulta, os acompanhantes destacam aspectos do relacionamento interpessoal que favorecem a confiança no profissional e em suas condutas: a forma de conversar, a apresentação pessoal e o oferecimento de explicações por parte do profissional.

No que respeita à maneira como o profissional se dirige aos acompanhantes, a maioria dos sujeitos é chamada por seus respectivos nomes ou por sua relação com a criança, isto é, mãe, pai, avó. Em geral, os participantes não expressam sentimento negativo por serem chamados por um qualificativo ao invés do nome.

E25: "Como eu tenho uma relação muito forte com a médica dela, ela me chama pelo nome".

E11: "apesar de não chamar pelo nome, 'mãe', uma palavra muito bonita mãe, eu me sinto bem com isso".
Comportamentos não interativos são referidos como causa de desagrado pelo atendimento. Alguns afirmam a freqüência de situações em que o profissional se detém a perguntar sobre o problema, e sequer olha para o acompanhante.

E10: "Não falam meu nome, só falam o que a criança tem, escrevem lá e pronto (...) não fico muito satisfeita, aqui só em caso de necessidade, por isso eu pago convênio. Aqui não dão atenção".

Quanto à apresentação pessoal do profissional ao início do atendimento, foi destacado que esse comportamento nem sempre está presente. Assim, os acompanhantes tentam identificar o nome do profissional em seu crachá, quando é agendada a consulta, ou na assinatura da receita.

E10: "no convênio se apresentam, é a primeira coisa que eles fazem (...) é melhor, porque lá você pode cobrar, você paga, então, você pode cobrar”.

Percebe-se nos relatos que a identificação do profissional também é importante, pois é o momento em que se inicia a relação entre profissional e familiar, e possibilitaria estabelecer uma boa comunicação e diálogo.

E19: "Me sinto mal mesmo, porque acho que deve ter diálogo entre o médico e a mãe da criança, todo médico tem que ter um diálogo. Então, fica chato”.

\section{Sentimentos e reações frente à consulta que não atende às expectativas}

Os sujeitos relatam sentimentos de chateação, raiva, desconforto, frustração e rejeição frente a consultas insatisfatórias, isto é, quando os profissionais não buscam evidências e não identificam o problema da criança, ou não orientam o familiar a respeito do problema.

E6: "Eu me sinto péssima, porque muitas vezes a gente não tem condições de ter um convênio e ter um bom atendimento médico e pra isso a gente recorre ao governo. Quando a 
gente vem, fala do problema para o médico e ele não dá atenção, ele não aprofunda no problema, quer dizer, é a mesma coisa que nada”.

Pode-se ainda identificar a desesperança dos acompanhantes quanto à melhoria do atendimento, quando manifestam que já se conformaram com o atendimento ruim e só procuram pelo serviço em emergências, preferindo usar o convênio privado de saúde.

E18: "Várias vezes a gente já passou por isso. Mas a gente vai fazer o que?”

Alguns afirmam reagir ou ter intenção de fazê-lo, se necessário, seja mediante reclamações diretas ao profissional que fez o atendimento, busca de outro profissional ou serviço, reclamações formais e não adesão ao tratamento prescrito quando não se sentem satisfeitos com o atendimento. Os que relatam reações de reclamação, também informam que os resultados dessas reações são positivos.

E6: "O médico foi agressivo na hora, só que eu debati com ele (...) [ele] disse que isso não era problema dele, que ele não ia me encaminhar exames, que não ia fazer a consulta, aí eu disse que ele não ia descontar os problemas dele na minha pessoa (...) se eu não tivesse o problema eu não teria ido lá, não teria esperado tanto, aí ele ficou mais calmo, ele foi super educado, me atendeu, me passou a receita”.

Há ainda relatos de não realização de tratamento prescrito por desconfiança da qualidade do atendimento.

E9: "Deixei a receita lá, porque ele nem olhou na minha cara e nem examinou. Como que ele ia saber o que eu tinha? (...) Mesmo pagando tive um mau atendimento".

\section{A troca de informações na consulta}

Os acompanhantes questionam o profissional quando têm dúvidas, comportamento que mostra seu empenho para compreender e, assim, seguir as ações prescritas de forma coerente:

E13: "Saio super esclarecida, se tem exame pra fazer, pergunto o nome do medica- mento, se tem que comprar (...) já estou craque já, de tanto perguntar”.

Apenas dois acompanhantes mencionaram que não fazem perguntas, seja por considerar que o profissional fará as orientações que achar relevantes e convenientes para o momento e, caso não concorde com o profissional, procurará pelo serviço de saúde particular, seja devido à timidez.

E10: "Eu nem pergunto, vou direto para o convênio, porque se ele não falou, é porque não quer falar”.

E24: "porque sou meio acanhado com médico, o que ele fala pra mim e eu acho meio suspeito não falo nada, se ele não me perguntar eu também não falo nada”.

\section{Organização dos resultados segundo a taxonomia de necessidades de Matsumoto}

A "Necessidade de garantia de acesso a todas as tecnologias" é manifestada quando os acompanhantes referem-se às razões para a busca de consultas na UBS e quando afirmam que o profissional deve buscar evidências sobre a situação da criança, identificando o diagnóstico e os fatores relacionados, para propor uma conduta; ainda, quando se referem à ausência desses comportamentos, isto é, que muitas vezes não recebem explicações e o diagnóstico não é preciso por falta de evidências.

A "Necessidade de ter vínculo com um profissional ou equipe" aparece nas demandas de atenção, segurança, carinho e interesse por parte do profissional, bem como de conhecer o profissional responsável pelo atendimento; é também evidente nos sentimentos vividos quando a relação não ocorre dessa forma.

A "Necessidade de boas condições de vida” é manifestada na busca de outros serviços, ou profissional, na postura de reivindicação de melhoria do atendimento, ou na não adesão ao tratamento.

A "Necessidade de autonomia e autocuidado na escolha do modo de 'andar a 
vida'” aparece especialmente nas demandas de informações sobre a saúde infantil e sobre as condutas a serem adotadas, que garantiriam ao responsável as condições necessárias para dar seguimento ao cuidado da criança no domicílio.

\section{DISCUSSÃO}

Conforme os resultados obtidos, as expectativas dos acompanhantes das crianças às consultas de saúde manifestam necessidades que merecem ser relevadas durante a assistência. Embora os relatos apontem várias experiências positivas, também destacam a irregularidade delas, pois não ocorrem com quaisquer profissionais e sim com alguns em particular, seja nas Unidades Basicas de Saúde estudadas, seja em outros serviços. Para explicar seu desagrado, alguns acompanhantes comparam o atendimento recebido nas UBS e em outros locais, como o hospital universitário da Universidade de São Paulo e serviços de convênio, destacando a maior resolubilidade destes dois últimos. Contudo, também há referências a atendimentos ruins em instituições conveniadas.

Isso aponta para a importância de entender melhor suas necessidades, de forma a qualificar adequadamente a atenção, foco deste estudo que buscou captar a perspectiva do usuário e analisar se a assistência nos serviços de saúde vai ao encontro das necessidades do acompanhante da criança às consultas, tendo por base suas expectativas sobre a atenção, como se discute a seguir.

A "Necessidade de boas condições de vida” não aparece na perspectiva ampla da demanda por melhores condições de trabalho e vida, mas num recorte de busca de melhor qualidade no atendimento. Ao comparar o atendimento nos serviços público e privado, alguns acompanhantes consideram a boa qualidade mais presente nos serviços privados, caracte- rizando dificuldade de acesso a boas condições de atenção à saúde.

No que se refere à "Necessidade de garantia de acesso a todas as tecnologias", destaca-se que o acesso às tecnologias de saúde na assistência visa promover melhor qualidade de vida ao indivíduo. Dado que o autor não explicita a que se refere por tecnologias e que este termo também se reveste de caráter multifacetado, para a análise dessa necessidade, faz-se primordial situá-lo.

O Ministério da Saúde define como tecnologias em saúde "medicamentos, equipamentos e procedimentos técnicos, sistemas organizacionais, educacionais, de informação e de suporte e os programas e protocolos assistenciais, por meio dos quais a atenção e os cuidados sanitários são prestados à população" ${ }^{11}$. De maneira mais abrangente, propõese três classificações ${ }^{12}$ : a) a tecnologia "dura" inclui as ferramentas-máquinas como aparelhos de raios-x, instrumentos para fazer exames de laboratórios, instrumentos para examinar o "paciente", prontuários de pacientes; b) a tecnologia "leve-dura" refere-se ao conhecimento ou a protocolos de atendimento. É leve por ser um saber adquirido e utilizado para pensar os casos de saúde e organizar uma atuação sobre eles, mas é dura, pois é um saber-fazer bem estruturado; c) e a tecnologia "leve" corresponde às relações entre o profissional e o usuário.

Os resultados do presente estudo evidenciam, em sua maioria, uma adequada relação entre a demanda e a oferta de tecnologias duras e leve-duras, trazendo resolubilidade e, portanto, satisfação ao usuário. A resolubilidade também é um fator importante para que o usuário tenha confiança no trabalhador e no serviço, criando vínculos com estes.

Por outro lado, algumas situações em que os acompanhantes não obtiveram consultas ou exames especializados foram descritas como negativas, porque eles não puderam acessar todas as tecnologias para atender a criança. O mesmo ocorre nos casos em que o 
diagnóstico e o tratamento proposto não foram resolutivos.

$\mathrm{O}$ acesso às tecnologias leves, especificamente, aloca-se na segunda categoria: a " $\mathrm{Ne}$ cessidade de ter vínculo com um profissional ou equipe”. O vínculo contempla questões complementares: a relação entre os sujeitos e a promoção de sua autonomia nessa relação. Ele é possível se a relação é interativa e produz acolhida das intenções das pessoas no encontro, responsabilização conjunta em torno do problema que vai ser enfrentado, e confiabilidade e esperança ${ }^{12}$.

A necessidade de vínculo foi evidenciada nas definições de atendimento bom e ruim. Assim, o estabelecimento de vínculo qualifica a consulta, por se relacionar ao atendimento de uma necessidade dos usuários.

As expectativas e necessidades dos usuários quanto à consulta da criança descritas neste estudo são similares às de estudos realizados em Santa Catarina ${ }^{13,14}$ : as mães valorizam sobremaneira as interações atenciosas, reconhecidas pelo interesse dos profissionais em investigar com minúcia a situação da criança, dar explicações e orientá-las sobre o cuidado infantil. Em relação à percepção sobre o atendimento recebido, as mães daqueles estudos consideram boas as práticas de atenção dos estudantes e relatam que as melhores práticas de interação ocorrem nos contatos com os pediatras. Diferentemente da pesquisa catarinense, a presente tratou da atuação de enfermeiras e médicos generalistas nas consultas.

Outros estudos mostram que a maioria dos pais deseja desenvolver um relacionamento com os profissionais no cuidado de suas crianças ${ }^{15,16}$. O usuário, ao procurar pelo serviço de saúde, espera que a relação com os profissionais gere acolhimento e permita uma atuação sobre o seu sofrimento, ou problema, uma vez que a condição para avaliação e terapêutica correta é que ele e/ou a criança sejam vistos e ouvidos efetivamente. Para haver tal vínculo, exige-se a assunção do usuário à condição de sujeito que fala e julga, sem o que não se estabelecem relações adequadas.

Estudo sobre a consulta médica no Estado da Bahia ${ }^{17}$ mostrou que, enquanto a abordagem clínica do médico se circunscrever à queixa, ao fenômeno físico, o encontro entre o médico, a criança e sua família dar-se-á, meramente, formalmente pela prescrição de medicamentos visando a remissão de sintomas. Por outro lado, entende-se que, se a queixa, juntamente com outros elementos, possibilitar a apropriação das condições de vida das crianças assistidas, o papel do profissional poderá superar a moldura da consulta. Dessa maneira, a construção de vínculo com a família da criança é construída, de forma que o profissional proporciona meios de ir além da pontualidade da queixa, através da interação com a mãe ou responsável pela criança possibilitando uma consulta semelhante num espaço doméstico e comunitário, com seus limites reais e suas potencialidades ${ }^{17}$.

O terceiro conjunto trata da "Necessidade de autonomia e auto-cuidado na escolha do modo de 'andar a vida'", e se relaciona ao objetivo de ampliar a capacidade do paciente para "melhorar seu entendimento do próprio corpo, da sua doença, de suas relações com o meio social”"18, isto é, sua autonomia. A autonomia depende de uma combinação de técnicas de apoio individual ${ }^{12}$, tais como medicação, atenção clínica, acesso às informações, reabilitação física e referência em casos de crises, que devem ter como função possibilitar ao usuário fazer escolhas fundamentadas sobre o cuidado de saúde. Em relação às informações e orientações, a maioria dos acompanhantes deste estudo refere recebê-las adequadamente, ou após solicitação de esclarecimentos.

Há usuários que recorrem prioritariamente a serviços de urgência e emergência, e se sentem bem com isso, pois não têm interesse em estabelecer uma relação mais permanente com os trabalhadores de saúde ${ }^{18}$. Isso não é 
evidenciado neste estudo, cujos sujeitos afirmam o desejo de atenção individualizada e de seguimento, como também fazem depoimentos que denotam desesperança e desconforto frente aos atendimentos considerados ruins, porque não possibilitam proximidade com o profissional. Tal fato pode ser relacionado a características específicas dos participantes, mas também por se tratar de atendimento de crianças que, por suas peculiaridades de desenvolvimento, apresentam demandas contínuas de atenção de saúde.

Por outro lado, vê-se que os sujeitos não possuem autonomia nas decisões referentes ao acesso ao atendimento, seja porque a demanda do serviço de saúde é muito grande, gerando longos períodos de espera para agendamento e atendimento, seja porque não podem escolher o profissional que vai atendê-los.

Dentre os princípios do HumanizaSUS ${ }^{8,9}$ para a qualificação da saúde pública, destacamse neste estudo a autonomia e a emancipação dos sujeitos em interação no momento da consulta. Os resultados evidenciam maior atenção às necessidades dos acompanhantes nos momentos da consulta de saúde, ou puericultura. Contudo, quando há distúrbios orgânicos, nem sempre tais necessidades são respeitadas, especialmente no que se refere à resolubilidade. Nesse sentido, a adoção de um modelo sistematizado de atendimento, como é o caso da Estratégia de Atenção Integral às Doenças Prevalentes da Infância poderia constituir-se num recurso para o profissional focar a avalia- ção dos principais sinais de doenças infantis, proporcionando maior resolubilidade ${ }^{19}$.

Assim, a revisão de tecnologias e ações de saúde deve ter em vista a centralidade da família no cuidado da criança, o que demanda o compromisso ético e de responsabilidade do profissional na produção desse cuidado, mediante investimento em sua formação permanente.

Os acompanhantes manifestam expectativas de receberem atendimento resolutivo, mediante relações interpessoais permeadas por atenção e respeito. Há variações no que é considerado resolutivo, mas percebe-se maior insatisfação em relação às consultas quando a criança está doente do que nas de puericultura.

Os resultados reafirmam a importância de que os profissionais se dediquem não só a esclarecer as dúvidas e preocupações dos acompanhantes, como também a proporcionar relações consistentes, gerando confiança no atendimento e nas recomendações. Assim, os sujeitos da pesquisa reforçam a idéia inicial de que a assistência efetiva é aquela baseada na compreensão empática da pessoa em todos os seus aspectos e no atendimento às diversas necessidades sentidas.

Sabe-se que diversos fatores influenciam as práticas de saúde, além dos individuais mas, tendo em vista que a integralidade da atenção favorece a população, bem como os profissionais, que podem se perceber mais efetivos em sua atuação, este estudo poderá contribuir para mudanças de suas práticas, em defesa do bemestar e do cuidado infantil. 


\section{REFERÊNCIAS}

1. Wright J, Williams R, Wilkinson JR. Health needs assessment: Development and importance of health needs assessment. $\mathrm{Br}$ Med J. 1998; 316(7140):1310-3.

2. Jordan J, Wright J. Making sense of health needs assessment. Br J Gen Pract. 1997 November; 47(424):695-6.

3. Macfarlane J, Holmes W, Macfarlane R, Britten, N. Influence of patient's expectations on antibiotic management of acute lower respiratory tract illness in general practice: questionnaire study. $\mathrm{Br}$ Med J. 1997; 315(7117):1211-4.

4. Werk LN, Bauchner H. Pratical considerations when treating children with antimicrobials in the outpatient setting. Drugs. 1998; 55(6):779-90.

5. Madeira AMF, Paulo IMA. Avaliação da consulta de enfermagem prestada à criança de 0 a 2 anos de idade em um Centro de Saúde. Rev Esc Enf USP. 1995; 29(3):23145.

6. Gonçalves RC, Oliveira I, Vênega NC, Kakehashi S, Sugai TA. Hospitalização conjunta mãe e filho no Hospital das Clínicas da Universidade Estadual de Campinas: avaliação de um grupo de mães. Rev Paul Enferm. 1992; 11(3):111-5.

7. Campos CMS, Bataiero MA. Necessidades de saúde: uma análise da produção científica brasileira de 1990 a 2004. Interface: Comunic, Saúde, Educ. 2007; 11(23):605-18.

8. Brasil. Ministério da Saúde. Secretaria de Atenção à Saúde. Política Nacional de Humanização da Atenção e Gestão do SUS. Clínica ampliada e compartilhada / Ministério da Saúde, Secretaria de Atenção à Saúde, Política Nacional de Humanização da Atenção e Gestão do SUS. Brasília: Ministério da Saúde; 2009 [acesso em 31 nov 2009] [cerca de 64 p]. Disponível em: http://bvsms.saude.gov.br/ b v s / p u b l i c a c o e s / clinica_ampliada_compartilhada.pdf
9. Brasil. Ministério da Saúde. SecretariaExecutiva. Núcleo Técnico da Política Nacional de Humanização. HumanizaSUS: Política Nacional de Humanização: a humanização como eixo norteador das práticas de atenção e gestão em todas as instâncias do SUS / Ministério da Saúde, Secretaria-Executiva, Núcleo Técnico da Política Nacional de Humanização. Brasília: Ministério da Saúde; 2004. [acesso em 31 nov 2009] Disponível em: http://bvsms.saude.gov.br/ bvs/publicacoes/humanizasus_2004.pdf

10. Matsumoto NF. Operacionalização do PAS de uma unidade básica de saúde do Município de São Paulo, analisada sob o ponto de vista das necessidades de saúde. [dissertação]. São Paulo: São Paulo: Escola de enfermagem, Universidade de São Paulo; 1999.

11. Ministério da Saúde. Secretaria de Ciência, Tecnologia e Insumos Estratégicos. Avaliação de tecnologias em saúde. Brasília (DF): Departamento de Ciência e Tecnologia - Decit. 2008 [acesso em 31 nov 2009] Disponível em: http:// bvsms.saude.gov.br/bvs/publicacoes/ avaliacao_tecnologias_saude.pdf

12. Merhy EE. O Ato de cuidar: a alma dos serviços de saúde. [Internet] 1999 [acesso em 31 nov 2009] Disponível em: http:// www.saude.to.gov.br/download/cges/ Referencias_Bibliograficas.doc

13. Cardoso PM, Grosseman S, Robles ACC. Percepções de mães sobre o atendimento prestado a seus filhos por acadêmicos da $11^{\text {a }}$ fase em um ambulatório de pediatria. ACM arq catarin. med. 2007; 36(3): 4251.

14. Périco GV, Grosseman S, Robles ACC, Stoll C. Percepção de mães sobre a assistência prestada a seus filhos por estudantes de medicina da sétima fase: estudo de caso no ambulatório de pediatria de um hospital universitário. Rev. bras. educ. méd. 2006; 30(2):49-55. 
15. Gore C, Johnson RJ, Caress AL, Woodcock A \& Custovic A. The information needs and preferred roles in treatment decision making of parents caring for infants with atopic dermatitis: a qualitative study. Allergy. 2005; 60(7): 938-43. In: Jackson R. Qualitative analysis of parents' information needs and psychosocial experiences when supporting children with health care needs. Health Info Libr J. 2007; 25(1):31-7.

16. Pyke-Grimm KA, Degner L, Small A \& Mueller B. Preferences for participation in treatment decision making and information needs of parents of children with cancer: a pilot study. J Pediatr Oncol Nurs. 1999; 16(1): 13-24. In: Jackson R. Qualitative analysis of parents' information needs and psychosocial experiences when supporting children with health care needs. Health Info Libr J. 2007; 25(1):31-7.
17. Lima IMSO, Alves VS, Franco ALS. A Consulta médica no contexto do programa saúde da família e direito da criança. Rev Bras Crescimento Desenvolv Hum. 2007; 17(3):84-94.

18. Merhy, EE. Em busca da qualidade dos serviços de saúde: os serviços de porta aberta para a saúde e o modelo tecnoassistencial em defesa da vida. In: Cecílio LCO. Inventando a mudança na saúde. São Paulo: Hucitec; 2006. p. 117-60.

19. WHO. Integrated Management of Childhood Illness (IMCI). Child and adolescent health and development. Western Pacific Region. 2008 [acesso em 31 nov 2009]; [cerca de 5 p]. Disponível em: http://www.wpro.who.int/NR/ rdonlyres/D5DE9C49-9431-4405-850A873C7CDD6464/0/07dhp.pdf

Recebido em 8 de agosto de 2009

Modificado em 3 de setembro de 2009

Aceito em 17 de novembro de 2009 